\title{
- Dental Practice during COVID-19
}

\section{Prabu Mahin Syed Ismail}

\section{IJCRR}

Section: Healthcare

ISI Impact Factor

(2019-20): 1.628

IC Value (2019): 90.81

SJIF (2020) $=7.893$

Department of Restorative Dentistry, College of Dentistry in Al-Rass Qassim University, Kingdom of Saudi Arabia.

E-mail:mahin_1973@yahoo.com

\section{INTRODUCTION}

COVID-19 is caused by a 2019 novel coronavirus, severe acute respiratory syndrome (SARS)-CoV-2 (SARS-COV-2) virus. (SARS)-CoV-2, belongs to subgenus sarbecovirus. It is responsible for the latest pandemic that is affecting human health and economy across the world. WHO declared the Chinese outbreak of COVID-19 as a Public Health Emergency. Healthcare providers are at an increased risk of contracting the infection and becoming potential carriers of the disease. ${ }^{1}$ Common symptom at onset of illness include fever, nonproductive cough, myalgia, or fatigue; less common symptoms are sputum production, headache, haemoptysis, and diarrhea. ${ }^{2,3}$ Person to person transmission occurs primarily via droplet spread or contact routes. Clinical management of COVID-19 is mainly symptomatic treatment. ${ }^{1}$

Covid 19 has affected the dental practice seriously. It has increased the anxiety and fear among practitioners due to the risk of transmission during dental procedure and higher morbidity rate. Dental team should update their knowledge and skills regarding infection control. The standard infection control measures should be followed in clinical practice. Good hand hygiene and infection protocol should be followed. Telephone triage and teledentistry should be encouraged. Social distancing can be maintained. Dental procedures should be classified as emergencies, urgent, and no urgent urgent dental procedures. Preprocedural mouth rinse with $0.5-1 \%$ hydrogen Peroxide should be followed. During procedures, personal protective equipment (PPE) and N95 masks or respirators should be used. ${ }^{3,4}$ Aerosols generating dental procedures such as the use of rotary instruments like scalers and handpieces should be avoided or used cautiously since it may cause a greater risk of contamination with oral secretions, saliva, or blood. ${ }^{1}$ Mopping of the floor with $1 \%$ sodium hypochlorite and disinfecting waterlines with $0.01 \%$ sodium hypochlorite can help in reducing the risk of crossinfection. ${ }^{1}$ Follow-up of infection control protocol and safety measures can prevent the transmission of the Covid -19 . Creating awareness can reduce the fear and anxiety among dental practitioners.

\section{REFERENCES}

1. Bhanushali P, Kate F, Deshpande S, Chimata VK, Shetty S, et al. COVID-19: Changing TrendsandIts ImpactonFuture of Dentistry. International Journal of Dentistry. Volume 2020, Article ID 8817424, 6 pages. https://doi.org/10.1155/2020/8817424

2. Huang C, Wang Y, Li X, et al. Clinical features of patients infected with 2019 novel coronavirus in Wuhan, China. The Lancet. 2020;395(10223):497-506, 2020.

3. Kathree BA, Khan SB, Ahmed R, Maart R, Layloo N, Asia-Michaels W (2020) COVID-19 and its impact in the dental setting: A scoping review. PLoS ONE. 2020. 15(12): e0244352.

4. Janakiram C, Nayar S, Varma B, et al. Dental Care Implications in Coronavirus Disease-19 Scenario: Perspectives. J Contemp Dent Pract 2020;21(8):935-941. 